International Journal of Medical Arts 2020; 2[1]: 199-203.

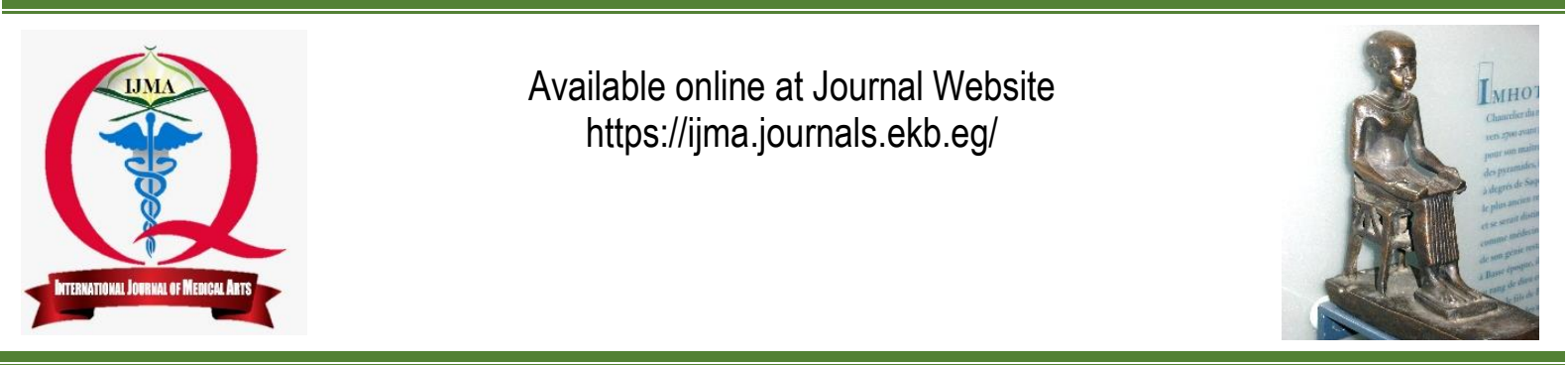

Original article

\title{
Pediatric Female with Adult Type Small Intestine Gastrointestinal Stromal Tumor [GIST]: A case report
}

\author{
Abdulmohsen Abdulla Alsuwaigh \\ Consultant General Laparoscopic and Bariatric Surgery, Laparoscopic and Bariatric Fellowship [Germany]; Faculty \\ of Health Science [Al-Ahsaa, Kingdom of Saudia Arabia] \\ Email: abdulmohsen4@hotmail.com \\ DOI: 10.21608/ijma.2019.63221
}

\section{ABSTRACT}

Background: Gastrointestinal stromal tumor [GIST] is commonest mesenchymal tumor, mainly affects adults. But, $1.5 \%$ to $2 \%$ GISTs were reported in pediatrics and adolescents. The treatment of GIST is managed as in adult because of lack of information about pediatric GIST.

Aim of the work: Here we presented a case report of pediatric GIST. Current literature was reviewed and a summary was formulated to form a base for future optimal treatment of childhood GIST.

Case summary: A 14 years Saudi female presented with vague abdominal pain and easy fatigability for 8 months. The pain located in lower abdomen, mild, waning, no aggravation or reliving factor and not radiating. Clinically, there was peri umbilical round, firm and not tender mass extending to right side of the abdomen till right hypochondrium, with no movement with respiratory movements. Investigations demonstrate severe microcytic hypochromic anemia. A computed tomography [CT] abdomen and pelvis showed evidence of soft tissue mass, about $13^{*} 11^{*} 12 \mathrm{~cm}$, of heterogeneous pattern and enhancement with area of hypodensity and cystic degeneration. There was necrosis of mesentery with some calcification seen inside the lesion suggestive of query GIST or Lymphoma. En block resection of the mass done with safety margin, biopsy from lymph node and side-to-side anastomosis done using linear stapler. The histopathological examination revealed ill and well defined fasicles of tumor cells that have spindle, oval and round shape nuclei invading mesentery and small bowel. Mitotic figurer 5-10/50 HPF, reactive lymph node. Immunohistochemistry showed diffused strong positive CD117 and CD34, negative S-100

Keywords: Pediatrics; Adolescents; Small Intestine; Gastrointestinal Stromal Tumor; Management. This is an open access article under the Creative Commons license [CC BY] [https://creativecommons.org/licenses/by/2.0/]

Please cite this article as: Alsuwaigh AA. Pediatric Female with Adult Type Small Intestine Gastrointestinal Stromal Tumor [GIST]: A case report. IJMA 2[1]: 199-203. 


\section{INTRODUCTION}

Gastrointestinal stromal tumor [GIST] is the commonest mesenchymal tumor related to gastrointestinal tract. It mainly affects adults. However, $1.5 \%$ to $2 \%$ GISTs were encountered in pediatrics and adolescents. The most common affected age in this category is 10 to 18 years of age [median age 13 years] ${ }^{[1]}$.

Mazur and Clarke ${ }^{[2]}$ coined the term GIST in 1983 for a distinct set of mesenchymal tumors of the GI tract having no ultrastructural or immunehistochemical features characteristic of smooth muscle differentiation.

Kindblom and associates[3] in 1998 showed that, GISTs actually originates from pluripotent mesenchymal stem cells that transformed into interstitial cells of Cajal. The latter are considered the "pacemaker cells" of gastrointestinal tract and responsible for initiation and regulation of gastrointestinal motility. Perhaps, the discovery of c-kit proto-oncogenes mutations represented the most crucial step which recognized GIST as a separate clinical condition ${ }^{[4]}$. These discovery leads the invention of molecular targeted therapy using tyrosine kinase inhibitors like imatinib mesylate. These agents act by competing for the ATP binding site on the target kinase, inhibiting tyrosine kinase and reducing cellular proliferation[5]. Pediatric intestinal leiomyosarcomas are extremely rare. The authors provide a description of a case of infantile, colonic intestinal leiomyosarcoma that was resected and classified histologically as grade 2 because of abundant mitoses. The tumor cells infiltrated serosa and submucosa. Immunohistochemically, cells were positive for alpha-smooth muscle actin but were negative to CD34 or CD117[6].

\section{Case report:}

A 14 years Saudi female presented to emergency room complaining of vague abdominal pain and easy fatigability for 8 months. The pain in the lower abdomen, not sever, on and off, no aggravation or reliving factor and not radiating to other side. Other $\mathrm{Gl}$ symptoms were normal. Physical examination demonstrates peri umbilical mass extending to right side of the abdomen till right hypochondrium, size $15^{\star} 12 \mathrm{~cm}$, round in shape, firm, not tender, not move with respiration, dull on percussion and the bowel sound is positive. Routine investigations were done which demonstrate severe microcytic hypochromic anemia. After routine work up investigation, CT abdomen and pelvis were done which showed that evidence of soft tissue mass measure about $13^{*} 11^{*} 12 \mathrm{~cm}$, showing heterogeneous pattern of enhancement with area of hypodensity with cystic degeneration, necrosis involving mesentery with some calcification seen inside the lesion suggestive of query GIST or Lymphoma [figure 1].

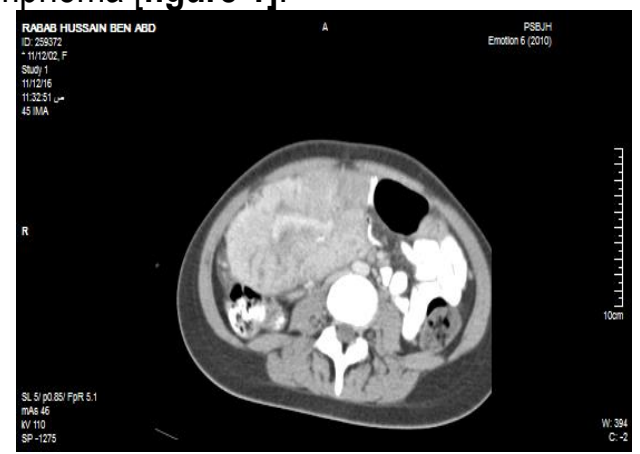

Figure [1]: Figure [1]: CT abdomen showed a lesion suggestive of query GIST or Lymphoma.

Computed tomography chest done and show no metastasis. Patient was prepared for exploratory laparotomy through midline incision and the findings were huge mass occupying the whole right side of the abdomen extending beyond the left side of the abdomen, it is about $15^{*} 12^{*} 8 \mathrm{~cm}$ in diameter and adhered to the small bowel and mesentery and multiple palpable mesenteric lymph nodes. The mass origin is from the anti-mesenteric part of the jejunum, $10 \mathrm{~cm}$ from DJ flexure. En block resection of the mass done with safety margin, biopsy from lymph node and side-to-side anastomosis done using linear stapler [figure 2a\&2b].

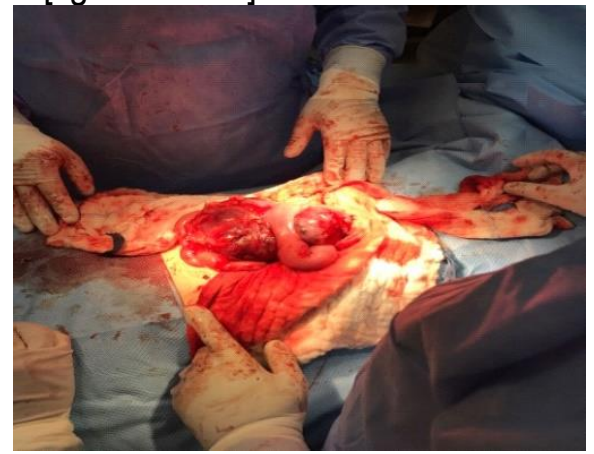

Figure [2A]: Mass in site after abdominal exploration 


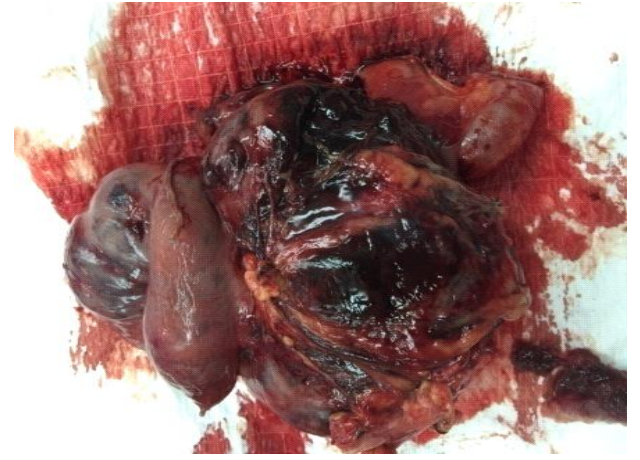

Figure [2b]: Mass after surgical removal

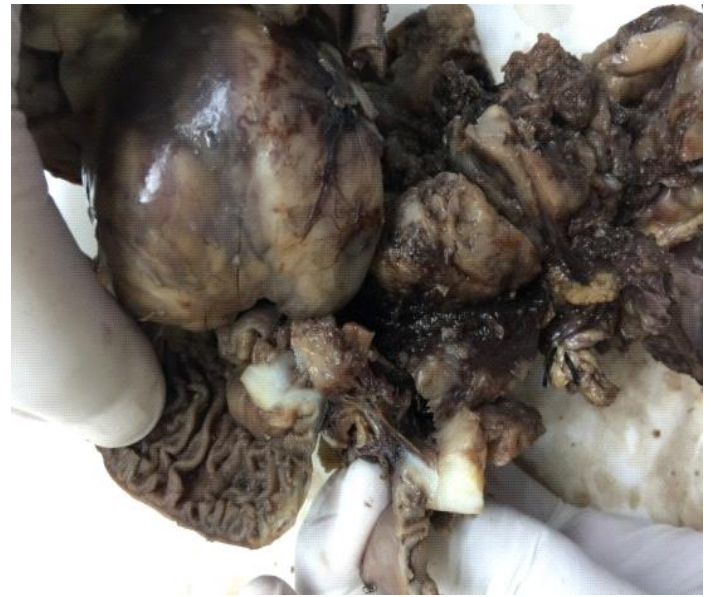

A

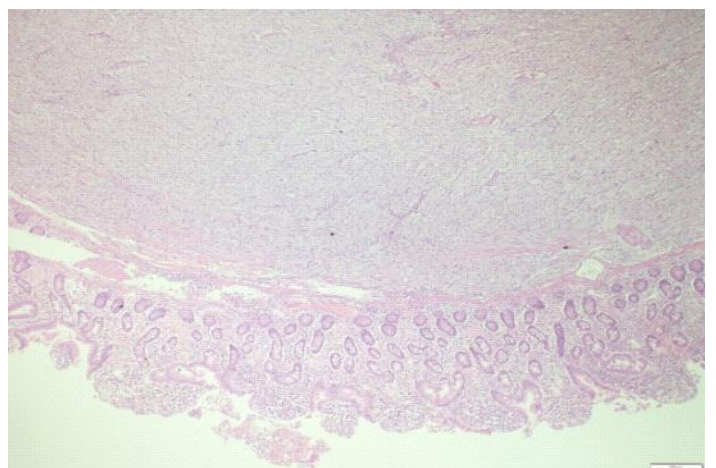

C1

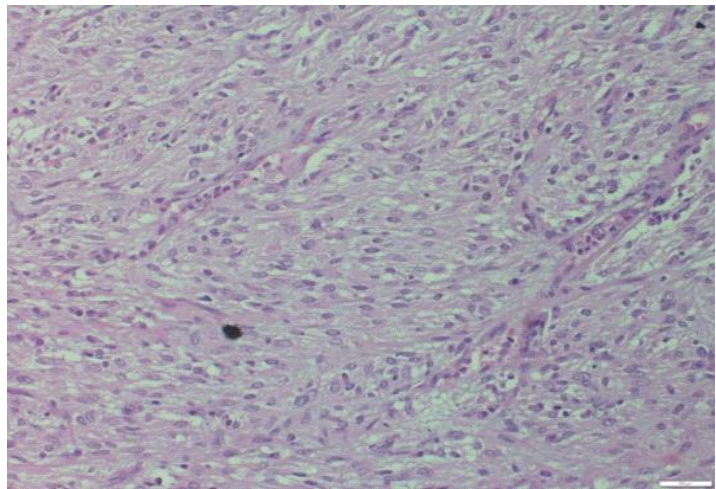

C3
Histopathology report revealed ill and well define fasicles of tumor cells that have spindle, oval and round shape nuclei invading mesentery and small bowel. Mitotic figurer 5-10/50 HPF, reactive lymph node. Immunohistochemistry showed diffused strong positive CD117 and CD34, negative S-100 [Figure 3 a, b \& c 1, 2, 3, 4]. Patient pass through uneventful postoperative period and discharge from our hospital in the 8th post-operative day and referred to oncology center.

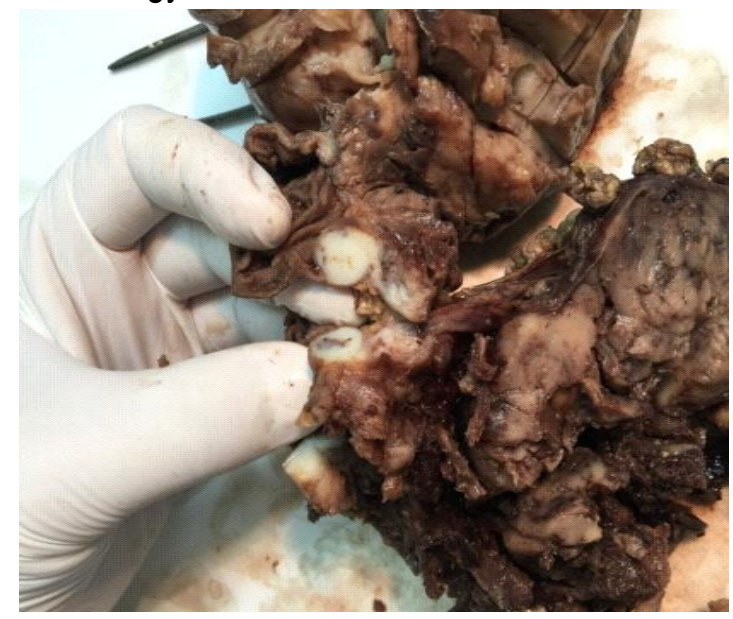

B

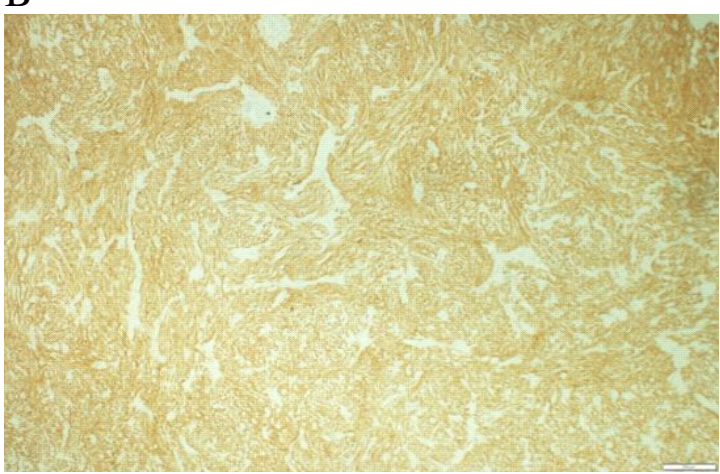

$\mathrm{C} 2$

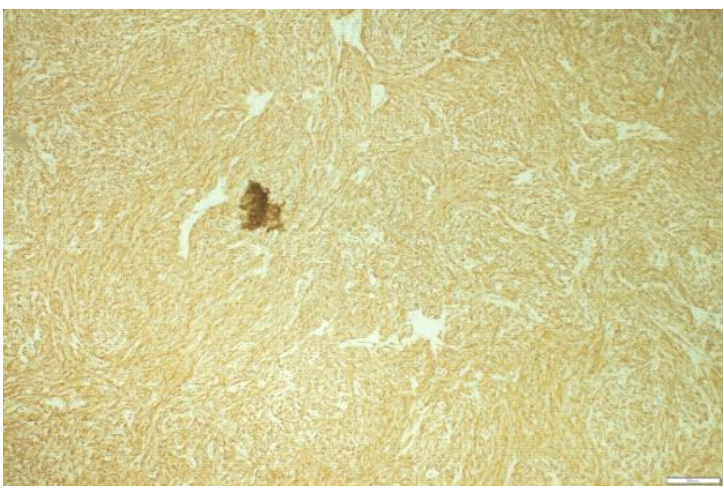

C4

Figure [3]: Gross and microscopic findings of excised mass 


\section{DISCUSSION}

GISTs differ markedly in pediatrics than in adults. Differences may be clinical, biologic and genetic which affects the strategy of management GISTs in pediatrics [7].

Pediatric GISTs usually discovered at ages between 10 and 18 years, with age of 13 as a median age ${ }^{[1]}$.

Pediatrics GISTs are rare, with female predominance, had multifocal locations in GIT, and had a wild-type phenotype for the c-kit genes. GISTs of small intestine had not yet categorized due to few number of cases [11 case reports in patients $<18$ years of age were reported] ${ }^{[8]}$.

The clinical presentation of GIST in pediatrics ranged between intestinal obstruction, intestinal mass or GIT bleeding[9].

Both Cajal and smooth muscle cells usually originates from the same precursor cells, and this accounts for the existence of both cells observed in many GISTs. In addition, the existence of GISTs in omentum and mesentery provide an evidence to predominance of Cajal cell phenotype. Electron microscopy confirms the hybrid nature of GISTs and this is consistent with origin from a multipotent precursor cell[10].

Although most of the GISTs occur sporadically, few familial GIST cases have been discovered. These cases reported as single tumors with mutations in the c-kit gene and not solely presented in females. This suggests that these cases are similar to adult GISTs ${ }^{[11]}$. In pediatric populations, GISTs arising from small intestine show a better response than gastric GIST to imatinib treatment due to mutations in the c-kit gene[8].

The complete surgical resection of GISTs is commonly practiced as the curative treatment in pediatrics. In one study, it was conducted for $80 \%$ [18 out 23 patients] and $90 \%$ of these patients complete their life with no recurrence. On the other side, complete surgical resection of GISTs has been reported in $40 \%$ of adult cases, with recurrence rate ranges from 40 to $80 \%$. These data suggest a more benign course for pediatric GISTs than in adult patients ${ }^{[12] .}$

In our study the patient was 14 years old female with intestinal GIST, adult type [+ve CD117], that was similar to the 11th cases reported previously.

\section{Conflict of interest}

Author declare that, there was no conflicts of interest.

\section{REFERENCES}

1. Kurucu N, Sari N CB, Celasun B, Sarihan H, Ahmetoglu A, Ilhan IE. Gastrointestinal stromal tumor in a newborn diagnosed in prenatal period: a case report and review of literature. J Pediatr Hematol Oncol. 2014; 36[8]:649. [DOI: 10.1097/MPH. 0b013e 3182a8f73f].

2. Mazur MT, Clark HB. Gastric stromal tumors. Reappraisal of histogenesis. Am J Surg Pathol. 1983; 7 [6]: 507-19. [DOl:10.1097/00000478-19830900000001]

3. Kindblom LG, Remotti HE, Aldenborg F, MeisKindblom JM. Gastrointestinal pacemaker cell tumor [GIPACT]: gastrointestinal stromal tumors show phenotypic characteristics of the interstitial cells of Cajal. Am J Pathol. 1998; 152:1259-1269. [PMID: 9588894].

4. Hirota S, Isozaki K, Moriyama Y, Hashimoto K, Nishida $T$, Ishiguro $S$, et al. Gain-of-function mutations of c-kit in human gastrointestinal stromal tumors. Science. 1998; 279:577-580. [DOI: 10.1126/ science.279. 5350.577].

5. Sashidharan P, Matele A, Matele U, Al Felahi N, Kassem KF. Gastrointestinal Stromal Tumors: A Case Report. Oman Med J. 2014; 29[2]:138-41. [DOI:10.5001/omj.2014.34].

6. Yamamoto H, Tsuchiya TY, Ishimaru Y, Kisaki Y, Fujino J, Uchida $\mathrm{H}$, et al. Infantile intestinal leiomyosarcoma is prognostically favorable despite histologic aggressiveness: case report and literature review. J Pediatr Surg. 2004; 39[8]:1257. [DOI:10.1016/ j.jpedsurg. 2004.04.021].

7. Dave M, Jimenez A, Evans K, Leslie W. Treatment of Recurrent Pediatric Gastrointestinal Stromal Tumors. Gastrointest Cancer Res. 2012;5[4]:139. [PMID: 23077690].

8. Shimomura M, Ikeda STY, Takakura Y, Kawaguchi Y, Tokunaga M, Takeda H, et al. Gastrointestinal stromal tumors of the small intestine in pediatric populations: a case report and literature review. Pediatr Surg Int. 2010 Jun; 26[6]:649-54. [DOl: $10.1007 /$ s00383-010-2596-3]. 
9. Kuroiwa M, Hiwatari MHJ, Hirato J, Suzuki N, Tsuchida $\mathrm{Y}$, et al. Advanced-stage gastrointestinal stromal tumor treated with imatinib in a 12-year-old girl with a unique mutation of PDGFRA. J Pediatr Surg. 2005; 40[11]:1798. [DOI:10.1016/j.jpedsurg. 2005. 07.066].

10. Manxhuka-Kerliu S, Sahatciu-Meka V, Kerliu I, Juniku-Shkololli A, Kerliu L, Kastrati M, Kotorri V. Small intestinal gastrointestinal stromal tumor in a young adult woman: a case report and review of the literature. J Med Case Rep. 2014; [8]:321. [DOI: 10.1186/ 1752-1947-8-321].
11. O'Sullivan MJ, McCabe GP, Gillett P, Penman ID, MacKinlay GA, Pritchard J. Multiple gastric stromal tumors in a child without syndromic association lacks common KIT or PDGFR alpha mutations. Pediatr Dev Pathol. 2005;8[5]:685. [DOI: 10.1007/s10024-0050083-y].

12. Chiarugi M1, Galatioto C, Lippolis P, Zocco G, Seccia M. Gastrointestinal stromal tumour of the duodenum in childhood: a rare case report. BMC Cancer. 2007; 2407[7]:79. [DOI: 10.1186/1471-24077-79]. 